\title{
Interleukin-1 and the NLRP3 Inflammasome in Pericardial Disease
}

\author{
Alessandra Vecchié ${ }^{1}$ - Marco Giuseppe Del Buono ${ }^{2}$ [D $\cdot$ Guido Juan Chiabrando ${ }^{3}$. Francesco Dentali ${ }^{4}$. \\ Antonio Abbate $^{2}\left(\mathbb{D}\right.$. Aldo Bonaventura ${ }^{1}(\mathbb{D}$
}

Accepted: 7 July 2021 / Published online: 1 October 2021

(C) The Author(s), under exclusive licence to Springer Science+Business Media, LLC, part of Springer Nature 2021

\begin{abstract}
Purpose of Review Pericarditis is a generally benign disease, although complications and/or recurrences may occur in up to $30 \%$ of cases. New evidence on the pathophysiology of the disease has accumulated in recent years.

Recent Findings Recently, it has been shown that the activation of the NLRP3 (NACHT, leucine-rich repeat, and pyrin domain-containing protein 3) inflammasome is central in the pathophysiology of pericarditis. These findings derive from clinical data, an experimental animal model of acute pericarditis supporting a role for the NLRP3 inflammasome in pericarditis, and from indirect evidence of inhibitors of NLRP3 inflammasome in clinical trials.

Summary Pericarditis is regarded as a stereotypical response to an acute damage of the mesothelial cells of the pericardial layers. NLRP3 inflammasome, a macromolecular structure sensing damage and releasing pro-inflammatory cytokines, is centrally involved as it releases interleukin (IL)-1 $\beta$, whose auto-induction feeds an autoinflammatory disease, mostly responsible for recurrences. Colchicine, an inhibitor of NLRP3 inflammasome formation, and IL-1-targeted therapies, such as anakinra and rilonacept, were found to effectively blunt the acute inflammation and reduce the risk for recurrences.
\end{abstract}

Keywords IL- 1 NLRP3 inflammasome $\cdot$ Acute pericarditis $\cdot$ Recurrent pericarditis $\cdot$ Anakinra $\cdot$ Rilonacept

\section{Introduction}

Acute pericarditis is the most frequent form of pericardial disease $[1,2]$. Data about its exact incidence are however few $[3,4]$. Although generally benign, current evidence suggests that a substantial number of complications may occur, with recurrences being particularly complex to treat and bothersome for patients [5].

This article is part of the Topical Collection on Pericardial Disease

Alessandra Vecchié

alessandra.vecchie@asst-settelaghi.it

1 Department of Internal Medicine, ASST Sette Laghi, Viale Luigi Borri, 57, 21100 Varese, Italy

2 Division of Cardiology, Department of Internal Medicine, Pauley Heart Center, Virginia Commonwealth University, Richmond, VA, USA

3 Cardiology Service, Hospital Italiano of Buenos Aires, Buenos Aires, Argentina

4 Department of Medicine and Surgery, Insubria University, Varese, Italy
The pathophysiology of pericarditis has also remained poorly understood for a long time [6]. The efficacy of colchicine demonstrated in randomized clinical trials including patients with acute and recurrent pericarditis (RP) [7-14] has spurred a lot of research. Indeed, colchicine is known to inhibit microtubule polymerization and block neutrophil migration [15], but also to interfere with the formation of the NACHT, leucine-rich repeat, and pyrin domain-containing protein 3 (NLRP3) inflammasome [16]. The encouraging results of the AIRTRIP (Anakinra-Treatment of Recurrent Idiopathic Pericarditis) trial [17] and other trials [18] using anakinra in acute and RP confirmed the hypothesis that the NLRP3 inflammasome is an important player in the pathophysiology of the disease. In light of these advancements, the treatment of pericarditis has indeed evolved, from nonsteroidal anti-inflammatory drugs (NSAIDs) $[1,18]$ to colchicine [8-14] and then up to targeted treatments against interleukin-1 (IL-1) $[17,18]$, the main product of the inflammasome.

In this narrative review, we explore the evidence linking the NLRP3 inflammasome and IL-1 to pericarditis pathophysiology. We will also discuss how to integrate IL-1 blockers in the treatment algorithm of the disease. 


\section{The NLRP3 Inflammasome and Interleukin-1 in Pericarditis}

\section{NLRP3 Inflammasome}

Pericarditis-either acute or recurrent-is characterized by inflammation of the pericardial sac. The local inflammation is then mirrored to a systemic level. Indeed, common inflammatory biomarkers-C-reactive protein (CRP), erythrocyte sedimentation rate (ESR), white blood cells (WBCs) - are increased in the majority of patients, although sensitivity and specificity are low [2]. No difference between sexes is usually observed, while younger patients ( $\leq 60$ years) present a more sustained inflammatory burden [19]. Importantly, persistently elevated highsensitivity CRP (hs-CRP) levels after 1 week of therapy were associated with an increased risk of recurrences (hazard ratio 2.36, 95\% confidence interval 1.32-4.21; $p<0.004)$ [20]. In a cohort of patients hospitalized for acute pericarditis, CRP and ESR levels were almost doubled in those experiencing worse outcomes, i.e., cardiac tamponade, constrictive pericarditis, therapy failure, recurrences, or death [5].

The inflammatory response occurring in pericarditis is to be considered as a stereotypical response to an acute damage of the mesothelial cells of the pericardial layers [21], usually initiated by a virus or any other trigger capable to stimulate the inflammatory response, then amplified through the activation of the NLRP3 inflammasome [22]. The NLRP3 inflammasome is a macromolecular structure found within the cytosol of several immune cells, especially macrophages and neutrophils. It is made up of three different components: (i) a sensor, NLRP3; (ii) an adaptor or scaffold protein, the apoptosis-associated speck-like protein containing a caspase recruitment domain (ASC), whose name comes from dense areas of aggregationspecks - providing evidence for the oligomerization of the inflammasome and; (iii) an effector protein, caspase-1, that cleaves pro-IL-1 $\beta$ and pro-IL-18 to their active forms and is responsible also for gasdermin $\mathrm{D}$ channels for the extracellular release of IL-1 $\beta$ and IL-18 [23, 24]. In most cells, NLRP3 inflammasome activation occurs through two steps: first, there is a priming step starting at the time of tissue injury through the release of danger-associated molecular patterns (DAMPs) that are responsible for promoting the transcription and translation of many proinflammatory genes, including the components of the NLRP3 inflammasome. The following step leads to the activation of the inflammasome through the oligomerization of the three components that is responsible for the typical stellate structure [24].

\section{Interleukin-1}

IL-1 family counts 11 cytokines, 10 receptors, and 4 coreceptors. Among IL-1 family members, IL-18 and IL-1 are the most well studied [23]. IL-1 exists in two isoforms. The expression of IL- $1 \beta$ is partly constitutive and partly induced as pro-IL-1 $\beta$, and requires processing by caspase1 in the inflammasome to be activated and secreted. It binds the IL- 1 receptor type 1 (IL-R 1 ), as such IL- $1 \beta$ functions as true cytokine [24]. IL-1 $\alpha$ on the other hand is largely constitutively present in mesenchymal cells as pro-IL- $1 \alpha$ and it is not cleaved by caspase- 1 nor cleavage is necessary for pro-IL- $1 \alpha$ to actively engage the IL-1R 1 , and as such IL- $1 \alpha$ functions mainly as an alarmin being released during cell injury.

A soluble receptor antagonist-IL-1 receptor antagonist ( $\mathrm{Ra}$ - _ binds the IL-1 receptor as IL- $1 \beta$ but it does not activate the intracellular signaling cascade. IL-1Ra is naturally produced alongside IL- $1 \beta$ and it is therefore a feedback mechanism to auto-regulate the inflammatory response. IL-1 $\beta$ has many pro-inflammatory effects, including the induction of prostaglandin and nitric oxide production, the increase in expression of leukocyte adhesion molecule, the activation of several cells involved in the inflammatory response, and the stimulation of cytokines expression [25]. Particularly, IL-1 $\beta$ stimulates various cell types to release IL-6 [26]. This cytokine acts on hepatocytes to induce the production of acute-phase reactants, such as CRP. IL-6 is itself a powerful pro-inflammatory cytokine further amplifying the inflammatory cascade.

In the cell, the decoy receptor IL-1R type 2 (IL-1R2) binds IL- $1 \alpha$ without transducing the inflammatory signal [27]. Soluble IL-1R2 also exists as a decoy anti-inflammatory receptor.

\section{NLRP3 Inflammasome/IL-1 Signaling Pathway in Pericarditis}

The tentative role of the NLRP3 inflammasome in the pathophysiology of pericarditis has been postulated in recent years. The first indirect clue relies on the use of colchicine as a first-line therapy [1]. Colchicine is known to inhibit microtubule polymerization and block neutrophil migration [15, 28], but has been also found to impair NLRP3 inflammasome activation [16, 29-31] by inhibiting microtubule assembly and presentation of the irritant agent to the inflammasome [29]. Another indirect clue comes from the The Anakinra-Treatment of Recurrent Idiopathic Pericarditis (AIRTRIP) study, where anakinra, a recombinant IL-1 Ra, was highly effective in reducing 
the risk of pericarditis recurrences in patients who were colchicine-resistant and glucocorticoid-dependent [17]. Recently, Mauro et al. showed that the NLRP3 inflammasome is activated within the inflamed pericardium [32•] (Fig.1). In samples from patients with chronic pericarditis experiencing an episode of acute pericarditis, activation of the NLRP3 inflammasome was more intense when compared with controls [32•]. This was also confirmed in a mouse model of acute pericarditis induced by the intrapericardial instillation of zymosan A. After 7 days from the acute injury, the presence of the three components of the inflammasome was markedly increased in the pericardium of zymosan A-treated mice compared with sham mice. As a further proof of it, treatment with colchicine, anakinra, and rilonacept (a dimeric fusion protein blocking IL- $1 \alpha$ and IL-1 $\beta$ ) was able to strongly reduce the expression of ASC, meaning that the NLRP3 inflammasome is neither oligomerized nor activated [32•]. This effect was also observed by treating mice with a specific NLRP3 inhibitor that was able to reduce pericardial effusion and thickness and ASC expression. By putting together this accumulating evidence, it is now apparent that the NLRP3 inflammasome plays a pivotal role in the pathogenesis of acute and RP and it represents an appealing therapeutic target [22].

\section{IL-1 Blockers for the Treatment of Pericarditis}

During the past decades, several IL-1 blockers have been developed for the treatment of many inflammatory diseases and are under investigations in the cardiovascular (CV) field.

Anakinra is approved for the treatment of several inflammatory diseases including cryopyrin-associated period syndromes (CAPS), genetic conditions characterized by enhanced NLRP3 inflammasome activity [33, 34] (Table 1). Anakinra binds IL-1R1 blocking both IL- $1 \alpha$ and IL-1 $\beta$ actions. Anakinra has a short halflife (4-6) and it is administered subcutaneously at the dose of $100 \mathrm{mg}$ once daily. The short half-life represents an advantage in case of adverse effects. The drug, however, has a favorable safety profile and local injection site reactions (ISR) are the most reported adverse events. Transient and self-limiting transaminase elevation has been reported in $10-30 \%$ of patients treated with anakinra (Table1). In rare instances, neutralizing autoantibodies are suspected in patients treated with anakinra who stop responding to the treatment.

Rilonacept is a chimeric fusion protein functioning as a soluble decoy that binds both IL- $1 \alpha$ and IL- $1 \beta$, approved

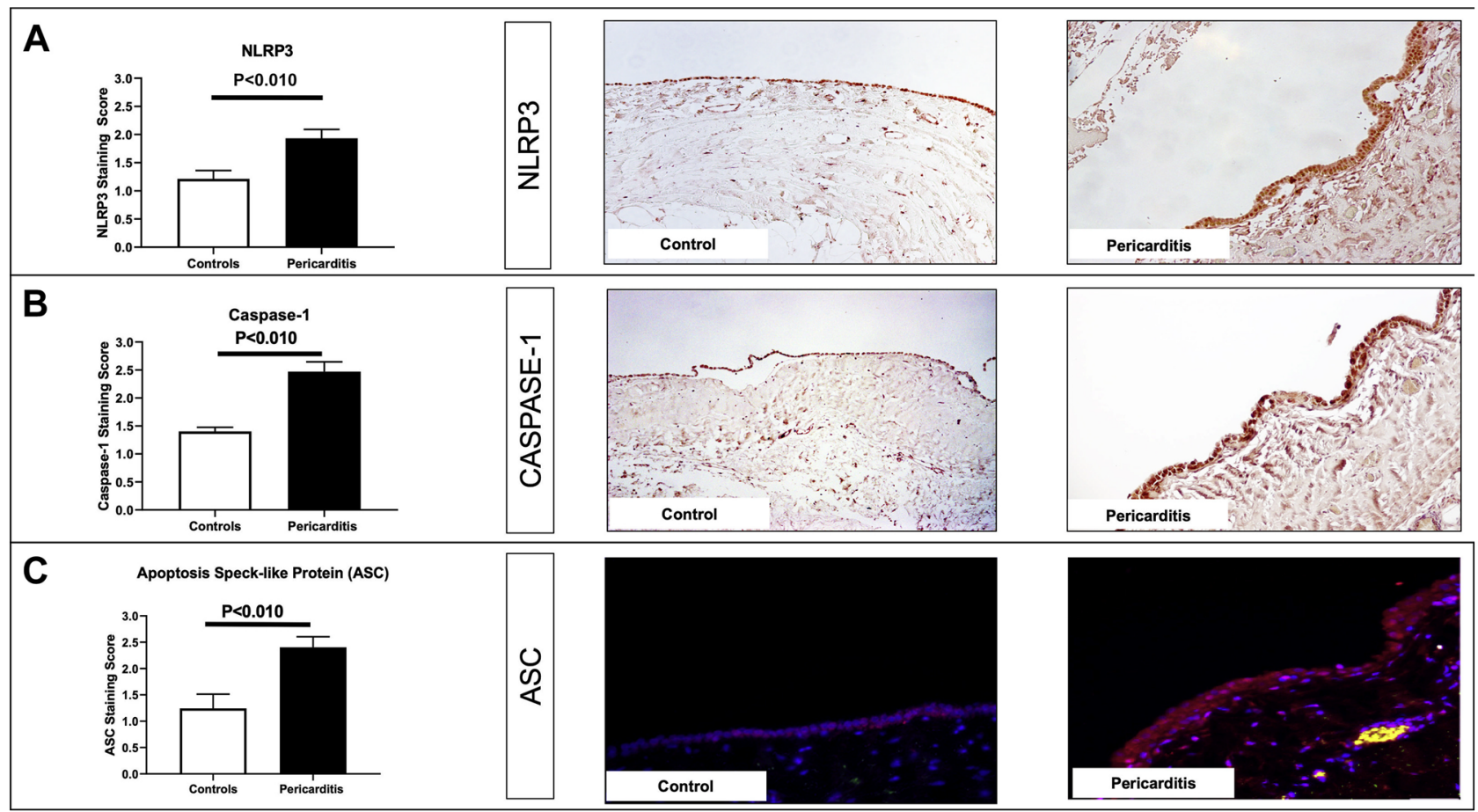

Fig. 1 The NLRP3 inflammasome is upregulated in patients with pericarditis. The three different components of the NLRP3 inflammasomeNLRP3, ASC, and caspase-1-are all more intensely expressed in the pericardium of patients with chronic pericarditis experiencing an acute flare. NLRP3 (A) and caspase-1 (B) have been revealed using immunohistochemistry, while ASC (C) has been detected through immuno- fluorescence staining and appears in red-specks are visible within the pericardium. For all pictures, counterstaining of the nuclei has been performed with DAPI (4',6-diamidino-2-phenylindole) and appears in blue. Original magnification for all pictures is $\times 40$. ([32•] Reproduced with permission from: Mauro AG et al. JACC Basic Transl Sci. 2021;6(2):137-50; with permission from Elsevier) 
Table 1 Anakinra and rilonacept characteristics

\begin{tabular}{|c|c|c|c|c|c|c|}
\hline & $\begin{array}{l}\text { Mechanism of } \\
\text { action }\end{array}$ & Indications & $\begin{array}{l}\text { Evidence of efficacy } \\
\text { in pericarditis }\end{array}$ & Dose & Duration of treatment & Adverse events \\
\hline Anakinra & $\begin{array}{l}\text { IL-1 receptor } \\
\text { antagonist }\end{array}$ & $\begin{array}{l}\text { Rheumatoid arthritis } \\
\text { Systemic Juvenile } \\
\text { Idiopathic Arthritis } \\
\text { Adult-Onset Still's } \\
\text { Disease } \\
\text { Familial Mediterranean } \\
\text { Fever } \\
\text { CAPS }\end{array}$ & $\begin{array}{l}\text { AIRTRIP trial }[17] \\
\text { IRAP registry Treat- } \\
\text { ment of Acute } \\
\text { Pericarditis with } \\
\text { Anakinra [45•] }\end{array}$ & $\begin{array}{l}2 \mathrm{mg} / \mathrm{kg} / \text { daily up } \\
\text { to } 100 \mathrm{mg} / \text { daily }\end{array}$ & $\begin{array}{l}\text { 3-6 months with } \\
\text { gradual tapering for } \\
\text { additionally } 3 \text { months }\end{array}$ & $\begin{array}{l}\text { Injection site } \\
\text { reaction } \\
\text { ALT and AST } \\
\text { elevation }\end{array}$ \\
\hline Rilonacept & $\begin{array}{l}\text { IL- } 1 \alpha \text { and IL-1 } \beta \\
\text { trap }\end{array}$ & CAPS & $\begin{array}{l}\text { RHAPSODY trial } \\
{[47 \bullet \bullet]}\end{array}$ & $\begin{array}{l}\text { Loading dose } \\
\text { of } 4.4 \mathrm{mg} / \mathrm{kg} \\
\text { up to } 320 \mathrm{mg} \\
\text { followed by } \\
2.2 \mathrm{mg} / \mathrm{kg} \text { up to } \\
160 \mathrm{mg} / \text { weekly }\end{array}$ & 6 months & $\begin{array}{l}\text { Injection site } \\
\text { reaction } \\
\text { (rare); } \\
\text { Upper res- } \\
\text { piratory tract } \\
\text { infection } \\
\text { (generally } \\
\text { mild) }\end{array}$ \\
\hline
\end{tabular}

$A L T$, alanine transaminase; $A S T$, aspartate transaminase; $C A P S$, cryopyrin-associated period syndromes; $I L$, interleukin

for the treatment of CAPS [35] (Table1). The long halflife of rilonacept represents an advantage for patients as it can be administered subcutaneously every 2 weeks at the dose of $160 \mathrm{mg}$ after a loading dose of $320 \mathrm{mg}$. As for anakinra, local ISR are the most common adverse events (Table1). Upper respiratory infection, generally mild and self-limiting, have been commonly reported in patients receiving rilonacept.

Several studies on the use of IL-1 blockers in the treatments of $\mathrm{CV}$ diseases have shown promising results. Acute myocardial infarction is associated with a strong inflammatory response which is directly correlated with poor outcomes [36]. In early phase clinical trials, the administration of anakinra for 14 days in patients with ST-segment elevation myocardial infarction led to a significant reduction in the acute inflammatory response along with a reduction of heart failure (HF) onset, of hospitalization for $\mathrm{HF}$, and of the combined outcome of death/HF onset and death/hospitalization for HF [37-39]. In patients with non-ST elevation ACS, the MRC-ILA Heart Study demonstrated the impact of IL-1 inhibition on inflammatory response reduction after 14 days of Anakinra administration [40].

Inflammation is highly involved in HF development. IL-1 has been recognized as a cardiodepressant factor in acute decompensated HF [41]. In an early phase clinical study, Anakinra has been shown to improve cardiorespiratory function and quality of life in patient with chronic stable HF [42]. In another study on patients hospitalized for decompensated $\mathrm{HF}$, treatment with anakinra reduced the inflammation and improved left ventricular ejection fraction [43]. A significant improvement in peak of oxygen consumption was observed in a pilot clinical phase II trial in patients recently hospitalized for acute decompensated HF treated with anakinra for
12 weeks [44]. These preliminary results are very promising, although further larger clinical trials are required in order to evaluate the use of anakinra as a routine treatment for patients with HF.

The efficacy of anakinra in the treatment of pericarditis was described in several reports and it has been recently confirmed in clinical trials. The AIRTRIP trial evaluated the effect of anakinra in RP [17]. The patients enrolled in this trial had RP resistant to colchicine and were dependent on glucocorticoids. After 60 days of treatment with anakinra, all of them were able to stop glucocorticoids therapy. After this first phase of the study, patients were randomized to continuation of anakinra or placebo. Among those who continued anakinra, only $10 \%$ experienced recurrences as compared with $82 \%$ in the placebo group [17].

In the International Registry of Anakinra for Pericarditis (IRAP), 224 consecutive patients with colchicine-resistant and glucocorticoid-dependent RP treated with anakinra were enrolled in 14 centers in 6 different countries [45•]. The aim of this observational study was the assessment of effectiveness and safety of anakinra in a "real-world" population. During the follow-up of 3889 patient-months, a $83 \%$ reduction in recurrence rate and a $91 \%$ reduction in emergency department admissions were observed. The majority of patients was able to discontinue glucocorticoids and NSAIDs. The subgroup of patients who discontinued anakinra after a slow tapering ( $>3$ months) showed the lower risk of recurrences compared with the group who stopped the drug abruptly and with patients who suspended the treatment after a shorter reduced dose regimen. According to previous data, ISR was the most frequent adverse event. Infections were reported in 6 patients $(3 \%)$, all resolved [45•]. 
The efficacy and safety of rilonacept for the treatment of RP were recently showed. A multicenter phase 2 trial enrolled 25 adults with idiopathic or post-pericardiotomy $\mathrm{RP}$, who had at least a second active recurrence at the time of enrollment or who had had at least 2 recurrent events and had steroids-dependence [46]. A rapid resolution of chest pain and a concomitant reduction of CRP levels were observed. All patients were able to suspend or reduce the dose of concomitant medications [46]. These results were confirmed in the RHAPSODY (Rilonacept Inhibition of Interleukin-1 Alpha and Beta for Recurrent Pericarditis: a Pivotal Symptomatology and Outcomes Study) phase 3 clinical trial $[47 \bullet \bullet]$. In the first phase of the study, all 86 patients enrolled received rilonacept. After 12 weeks, patients who showed a response to treatment $(n=61)$ were randomized to rilonacept continuation or placebo. Rilonacept was shown to greatly reduce the risk of pericarditis recurrence (7 vs $74 \%$, hazard ratio $0.04,95 \%$ CI $0.01-0.18$ ). Injection site reactions and upper respiratory infections were the most

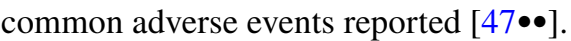

\section{Integration of IL-1 Blockers in the Treatment Algorithm of Pericarditis}

Based on latest European Society of Cardiology (ESC) guidelines for pericarditis, first-line therapies include NSAIDs and aspirin along with colchicine (class I, level of evidence A) [1] (Fig.2). The choice between NSAIDs (commonly ibuprofen, but also indomethacin or ketorolac) and aspirin should take into consideration the medical history of the patient and his/her comorbidities (e.g., aspirin to be favored for those needing an antiplatelet treatment). Low-dose, weight-adjusted colchicine is strongly recommended to increase the response to medical therapy and prevent recurrences $[8,12,48]$. Although tapering is not mandatory, it may be helpful to reduce symptom persistence and recurrences.

Second-line therapy includes glucocorticoids. The use of glucocorticoids, however, should be restricted to patients having contraindications for aspirin or NSAIDs, to those who had incomplete response with these treatments, or for specific indications, such as pericarditis associated with autoimmune diseases or related to immune checkpoint inhibitor therapy [2]. Glucocorticoids have been considered to favor a chronic disease and to increase the risk for recurrences along with causing drug dependence and should be used with colchicine $[1,9]$. Low-dose glucocorticoids (prednisone $0.2-0.5 \mathrm{mg} / \mathrm{kg}$ or equivalent) are advisable rather than high doses (prednisone $1 \mathrm{mg} / \mathrm{kg}$ or equivalent), because are associated with less recurrences, treatment failure, hospitalizations, and adverse effects [49, 50]. Patients receiving moderate to high doses of corticosteroids are at risk for developing Pneumocystis jirovecii pneumonia which is associated with a high mortality rate [51]. However, prophylaxis with cotrimoxazole is associated with potentially severe adverse events, including thrombocytopenia, pancytopenia, liver, and renal failure [51]. Therefore, there is not a consensus on the need of prophylactic measures in patients required glucocorticoids treatments and the decision
Fig. 2 Current treatments for acute and recurrent pericarditis, tamponade, and constrictive pericarditis. Based on 2015 ESC guidelines for pericarditis [1], treatments with dosing and duration are presented. IVIGs = intravenous immunoglobulins; $\mathrm{MMF}=$ mycophenolate mofetil. (Reproduced with permission from: Chiabrando JG, et al. J Am Coll Cardiol. 2020;75(1):76-92, with permission from Elsevier) [2]

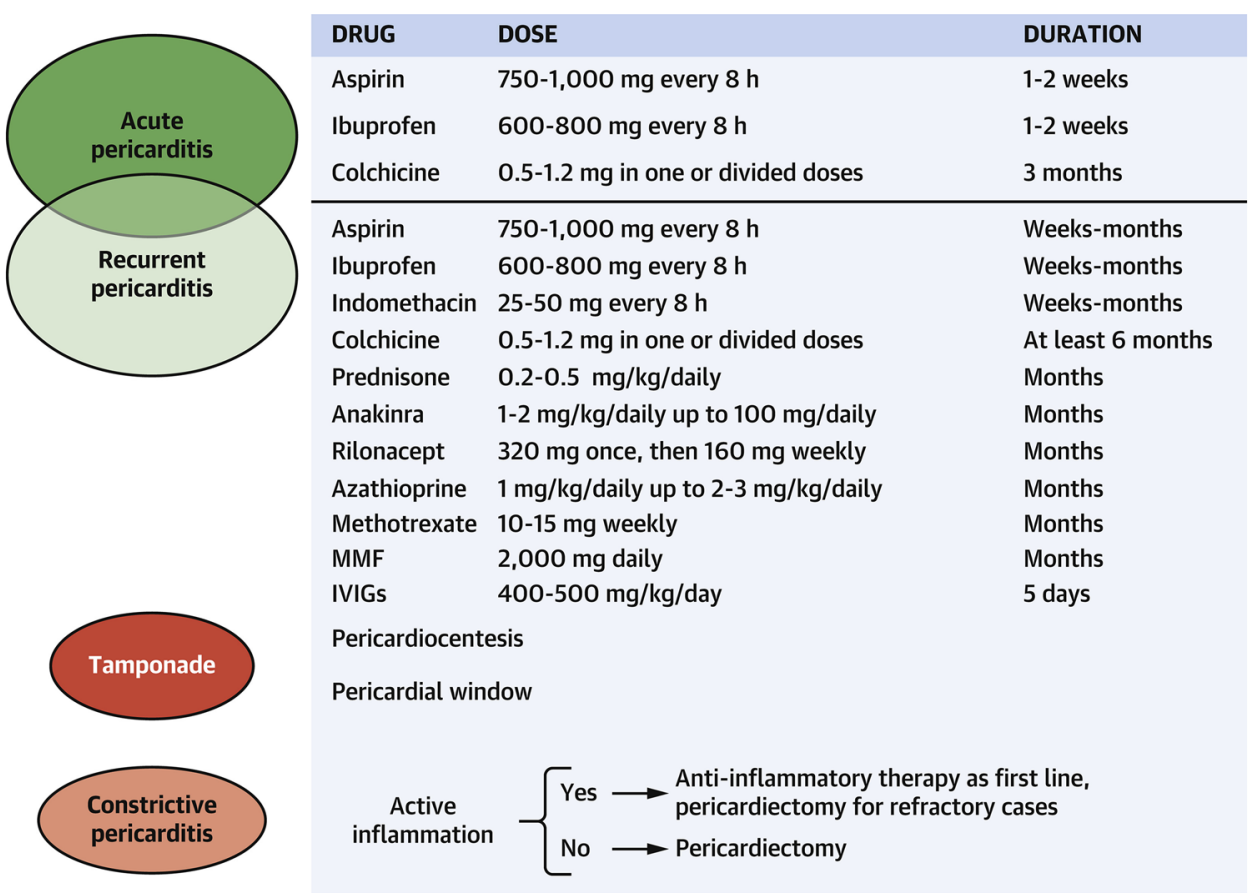


should be evaluated for each patient balancing specific risks and benefits. Glucocorticoid tapering should be started only after symptom resolution and normalization of inflammatory biomarkers (e.g., CRP $<3 \mathrm{mg} / \mathrm{L}$ ) $[1,2]$.

Considering the side effect profile and the high risk for recurrence and/or dependence, it is reasonable to skip treatment with glucocorticoids and consider an IL-1 blocker. In a small study including patients with acute pericarditis and not treated with glucocorticoids during the acute episode, administration of anakinra on the background of NSAIDs and colchicine (at least 2 doses) was able to significantly reduce pain soon after $6 \mathrm{~h}$ and IL-6 levels after $24 \mathrm{~h}$ [18]. Interestingly, reduction in pain symptoms after $24 \mathrm{~h}$ strongly correlated with reduction in IL-6 at $24 \mathrm{~h}$ [18]. Beneficial effects of anakinra were described also in patients who became glucocorticoid-dependent, thus confirming the additive effect of anakinra in blunting the acute inflammation and reducing further recurrences or hospitalizations $[17,45 \bullet$, $52,53]$.

Recent findings from the RHAPSODY trial with rilonacept showed a rapid resolution of the acute episode and a striking reduction in recurrence rates [47••], further supporting previous positive results with anakinra. At this time, ESC guidelines consider anakinra with a class II, level B recommendation suggesting administering anakinra to corticosteroid-dependent, colchicine-resistant patients with RP [1].

It is now apparent that although most patients respond to first-line therapies-NSAIDs and aspirin-a portion of them may not, requiring a second-line therapy. Following the encouraging results with IL-1 blockers, it might have come the time for these treatments to replace glucocorticoids that should be restricted to few, specific cases. Accordingly, the added value of IL-1 blockers resides in their ability to selectively block the main mechanism supporting the autoinflammatory nature of this disease, e.g., the NLRP3 inflammasome/IL-1 pathway signaling [22].

\section{Practical Considerations When Using Anakinra or Rilonacept for Recurrent Pericarditis}

Although not Food and Drug Administration (FDA)approved, Anakinra (Kineret $($ ) is given at a starting dose of $2 \mathrm{mg} / \mathrm{kg} /$ daily up to $100 \mathrm{mg} /$ daily, for those cases of RPresistant to colchicine and dependent on glucocorticoids, based on the positive results of the AIRTRIP trial [17]. Rilonacept (Arcalyst $($ ) ) is the first IL-1 blocker with an approved indication for recurrent pericarditis by the US Food and Drug Administration, and it is given as loading dose of $4.4 \mathrm{mg} / \mathrm{kg}$ up to $320 \mathrm{mg}$ followed by a weekly dose of 2.2 up to $160 \mathrm{mg} / \mathrm{kg}$. A progressive tapering is usually suggested after 6 months of controlled symptoms.
A common scheme for anakinra tapering is to reduce by $100-300 \mathrm{mg} /$ week every $1-2$ months and monitor for clinical activity and biomarkers [54]. As for rilonacept, there is no guidance as to whether tapering is needed, given the long half-life of the drug, and how to proceed. One commonly used approach with similar drugs is to prolong the interval between injections progressively from every 7 days to longer intervals, extending by $50 \%$ every $2-4$ weeks.

It is important to not discontinue colchicine in the meantime, while avoiding glucocorticoids.

Given its impact on the innate immune system, before starting the treatment with anakinra or rilonacept, all patients should be screened for any active infection, and, among those at risk, latent tuberculous infection (LTI) must be ruled out. Some authors also advise annual screening for LTI [55]. In addition, anakinra is contraindicated in patients with known hyper-sensitivity to proteins or any other product derived from Escherichia coli. Regular monitoring for neutrophil count is recommended once a month for the first 3 months and then quarterly for 1 year.

The most common adverse event is ISR [56]. The ISR are more common with anakinra and they present with burning feeling in the first weeks and typically disappears after the first month [57]. ISR are recorded in up to 70\% of patients; the large majority of them are mildly or moderately severe, leading to drug discontinuation in $<5 \%$ of patients [57]. In order to alleviate this reaction, the syringe should be warmed before the injection and a cool pack may be placed on the injection site few minutes before and after the administration of the drug. Delayed ISR may also occur, presenting with rash, swelling, pruritus, and pain with lesions containing eosinophils, mast cells, and macrophages looking like a typical allergic reaction [58]. This can be relieved using topical glucocorticoids or antihistamines, with resolution occurring in most cases within 2 months. Other adverse events occurring with both anakinra or rilonacept are serious infections [59, 60], usually including bacterial infections (cellulitis, bone and joint infections, and pneumonia) rather than opportunistic, fungal, or viral infections [56]. As anakinra and rilonacept may blunt the response to infections, discontinuation of the drug should be considered on a single-case basis by weighing risks and benefits. Indeed, anakinra has also been tested in patients with coronavirus disease 2019 (COVID19) [61-65] and sepsis [66], showing not to be harmful when infections are adequately managed. The response to most non-live vaccines (influenza, pneumococcal, tetanus toxoid, hepatitis B virus, and human papilloma virus among others) is adequately maintained with no major safety signals [67], especially when administered during the quietest phase of the disease. Since a suboptimal immune response is raised, an adjuvant or a booster dose may be needed [68]. In light of this, there is no reason to 
think that COVID-19 vaccine will be less effective. Live vaccinations, on the contrary, should not be use due to a theoretical risk [56], unless anticipated to 4 weeks prior to treatment start based on expert opinion [67].

\section{Conclusions}

Pericarditis pathophysiology has greatly evolved in past years, leading to a more targeted therapy. The latest 2015 ESC Guidelines suggested colchicine as first-line therapy along with NSAIDs. Colchicine's efficacy is considered to be related to its ability to block the NLRP3 inflammasome. Following the encouraging results of the AIRTRIP and RHAPSODY trials, IL-1 blockade has now a strong evidence as an additional therapeutic strategy for those patients who are colchicine-resistant or -intolerant and/or for those patients who are being considered for steroids or are steroiddependent. Future studies should keep on focusing on the NLRP3 inflammasome as a primary target in order to unravel further disease mechanisms and lead to novel targeted therapies for patients with RP.

\section{Compliance with Ethical Standards}

Conflict of Interest Dr. Bonaventura received a travel grant from Kiniksa Pharmaceuticals Ltd. and honoraria from Effetti s.r.l. (Milan, Italy).

Dr. Vecchié received a travel grant from Kiniksa Pharmaceuticals Ltd. and honoraria from Effetti s.r.l. (Milan, Italy).

Dr. Abbate has served as a consultant for Applied Clinical Intel, AstraZeneca, Cromos Pharma, Effetti s.r.l, Janssen, Kiniksa Pharmaceuticals Ltd., Eli Lilly, Merck, Olatec, Swedish Orphan Biovitrum, Novo Nordisk, and Serpin Pharma. He has also has received research support from Janssen, Olatec, Novartis, R-Pharm, and Serpin Pharma. In addition, Dr. Abbate has a patent Novel cryopyrin inhibitor issued, and a patent Alpha-1 antitripsin to treat cardiovascular conditions pending.

All other authors declare no competing interests.

Human and Animal Rights and Informed Consent This article does not contain any studies with human or animal subjects performed by any of the authors.

\section{References}

Papers of particular interest, published recently, have been highlighted as:

- Of importance

$\bullet$ Of major importance

1. Adler Y, Charron P, Imazio M, Badano L, Baron-Esquivias G, Bogaert J, et al. 2015 ESC Guidelines for the diagnosis and management of pericardial diseases: The Task Force for the Diagnosis and Management of Pericardial Diseases of the European
Society of Cardiology (ESC)Endorsed by: The European Association for Cardio-Thoracic Surgery (EACTS). Eur Heart J. 2015;36(42):2921-64. https://doi.org/10.1093/eurheartj/ehv318.

2. Chiabrando JG, Bonaventura A, Vecchie A, Wohlford GF, Mauro AG, Jordan JH, et al. Management of acute and recurrent pericarditis: JACC state-of-the-art review. J Am Coll Cardiol. 2020;75(1):76-92. https://doi.org/10.1016/j.jacc.2019.11.021.

3. Imazio M, Gaita F. Acute and recurrent pericarditis. Cardiol Clin. 2017;35(4):505-13. https://doi.org/10.1016/j.ccl.2017.07.004.

4. Kyto V, Sipila J, Rautava P. Clinical profile and influences on outcomes in patients hospitalized for acute pericarditis. Circulation. 2014;130(18):1601-6. https://doi.org/10.1161/ CIRCULATIONAHA.114.010376.

5. Vecchie A, Chiabrando JG, Dell MS, Bonaventura A, Mauro AG, Wohlford G, et al. Clinical presentation and outcomes of acute pericarditis in a large urban hospital in the United States of America. Chest. 2020;158(6):2556-67. https://doi.org/10.1016/j. chest.2020.07.039.

6. Bonaventura A, Montecucco F. Inflammation and pericarditis: are neutrophils actors behind the scenes? J Cell Physiol. 2019;234(5):5390-8. https://doi.org/10.1002/jcp.27436.

7. Rodriguez de la Serna A, Guindo Soldevila J, Marti Claramunt V, Bayes de Luna A. Colchicine for recurrent pericarditis. Lancet. 1987;2(8574):1517. https://doi.org/10.1016/s0140-6736(87) 92641-9.

8. Imazio M, Bobbio M, Cecchi E, Demarie D, Demichelis B, Pomari F, et al. Colchicine in addition to conventional therapy for acute pericarditis: results of the COlchicine for acute PEricarditis (COPE) trial. Circulation. 2005;112(13):2012-6. https:// doi.org/10.1161/CIRCULATIONAHA.105.542738.

9. Imazio M, Bobbio M, Cecchi E, Demarie D, Pomari F, Moratti $\mathrm{M}$, et al. Colchicine as first-choice therapy for recurrent pericarditis: results of the CORE (COlchicine for REcurrent pericarditis) trial. Arch Intern Med. 2005;165(17):1987-91. https://doi. org/10.1001/archinte.165.17.1987.

10. Imazio M, Trinchero R, Brucato A, Rovere ME, Gandino A, Cemin $\mathrm{R}$, et al. COlchicine for the Prevention of the Post-pericardiotomy Syndrome (COPPS): a multicentre, randomized, double-blind, placebo-controlled trial. Eur Heart J. 2010;31(22):2749-54. https:// doi.org/10.1093/eurheartj/ehq319.

11. Imazio M, Brucato A, Cemin R, Ferrua S, Belli R, Maestroni S, et al. Colchicine for recurrent pericarditis (CORP): a randomized trial. Ann Intern Med. 2011;155(7):409-14. https://doi.org/10. 7326/0003-4819-155-7-201110040-00359.

12. Imazio M, Brucato A, Cemin R, Ferrua S, Maggiolini S, Beqaraj $\mathrm{F}$, et al. A randomized trial of colchicine for acute pericarditis. N Engl J Med. 2013;369(16):1522-8. https://doi.org/10.1056/ NEJMoa1208536.

13. Imazio M, Belli R, Brucato A, Cemin R, Ferrua S, Beqaraj F, et al. Efficacy and safety of colchicine for treatment of multiple recurrences of pericarditis (CORP-2): a multicentre, double-blind, placebocontrolled, randomised trial. Lancet. 2014;383(9936):2232-7. https://doi.org/10.1016/S0140-6736(13)62709-9.

14. Imazio M, Brucato A, Ferrazzi P, Pullara A, Adler Y, Barosi A, et al. Colchicine for prevention of postpericardiotomy syndrome and postoperative atrial fibrillation: the COPPS-2 randomized clinical trial. JAMA. 2014;312(10):1016-23. https://doi.org/10. 1001/jama.2014.11026.

15. Paschke S, Weidner AF, Paust T, Marti O, Beil M, Ben-Chetrit E. Technical advance: inhibition of neutrophil chemotaxis by colchicine is modulated through viscoelastic properties of subcellular compartments. J Leukoc Biol. 2013;94(5):1091-6. https://doi. org/10.1189/jlb.1012510.

16. Marques-da-Silva C, Chaves MM, Castro NG, Coutinho-Silva R, Guimaraes MZ. Colchicine inhibits cationic dye uptake induced by ATP in $\mathrm{P} 2 \mathrm{X} 2$ and $\mathrm{P} 2 \mathrm{X} 7$ receptor-expressing 
cells: implications for its therapeutic action. Br J Pharmacol. 2011;163(5):912-26. https://doi.org/10.1111/j.1476-5381.2011. 01254.x.

17. Brucato A, Imazio M, Gattorno M, Lazaros G, Maestroni S, Carraro M, et al. Effect of anakinra on recurrent pericarditis among patients with colchicine resistance and corticosteroid dependence: the AIRTRIP randomized clinical trial. JAMA. 2016;316(18):1906-12. https://doi.org/10.1001/jama.2016.15826.

18. Wohlford GF, Buckley LF, Vecchie A, Kadariya D, Markley $\mathrm{R}$, Trankle CR, et al. Acute effects of interleukin-1 blockade using anakinra in patients with acute pericarditis. J Cardiovasc Pharmacol. 2020;76(1):50-2. https://doi.org/10.1097/FJC. 0000000000000847.

19. Lazaros G, Antonopoulos AS, Lazarou E, Vlachopoulos C, Vogiatzi G, Vassilopoulos D, et al. Age- and sex-based differences in patients with acute pericarditis. Eur J Clin Invest. 2021;51(3): e13392. https://doi.org/10.1111/eci.13392.

20. Imazio M, Brucato A, Maestroni S, Cumetti D, Dominelli A, Natale G, et al. Prevalence of C-reactive protein elevation and time course of normalization in acute pericarditis: implications for the diagnosis, therapy, and prognosis of pericarditis. Circulation. 2011;123(10):1092-7. https://doi.org/10.1161/ CIRCULATIONAHA.110.986372.

21. Buckley LF, Viscusi MM, Van Tassell BW, Abbate A. Interleukin-1 blockade for the treatment of pericarditis. Eur Heart J Cardiovasc Pharmacother. 2018;4(1):46-53. https://doi.org/10.1093/ehjcvp/ pvx018.

22. Bonaventura A, Vecchie A, Mauro AG, Brucato AL, Imazio M, Abbate A. An update on the pathophysiology of acute and recurrent pericarditis. Panminerva Med. 2020. https://doi.org/ 10.23736/S0031-0808.20.04205-6.

23. Abbate A, Toldo S, Marchetti C, Kron J, Van Tassell BW, Dinarello CA. Interleukin-1 and the inflammasome as therapeutic targets in cardiovascular disease. Circ Res. 2020;126(9):1260-80. https://doi. org/10.1161/CIRCRESAHA.120.315937.

24. Mauro AG, Bonaventura A, Mezzaroma E, Quader M, Toldo S. NLRP3 inflammasome in acute myocardial infarction. J Cardiovasc Pharmacol. 2019;74(3):175-87. https://doi.org/10.1097/ FJC.0000000000000717.

25. Libby P. Interleukin-1 Beta as a target for atherosclerosis therapy: biological basis of CANTOS and beyond. J Am Coll Cardiol. 2017;70(18):2278-89. https://doi.org/10.1016/j.jacc.2017.09.028.

26. Loppnow H, Libby P. Proliferating or interleukin 1-activated human vascular smooth muscle cells secrete copious interleukin 6. J Clin Invest. 1990;85(3):731-8. https://doi.org/10.1172/JCI114498.

27. Zheng Y, Humphry M, Maguire JJ, Bennett MR, Clarke MC. Intracellular interleukin-1 receptor 2 binding prevents cleavage and activity of interleukin-1alpha, controlling necrosis-induced sterile inflammation. Immunity. 2013;38(2):285-95. https://doi. org/10.1016/j.immuni.2013.01.008.

28. Bhattacharyya B, Panda D, Gupta S, Banerjee M. Anti-mitotic activity of colchicine and the structural basis for its interaction with tubulin. Med Res Rev. 2008;28(1):155-83. https://doi.org/ 10.1002/med.20097.

29. Martinon F, Petrilli V, Mayor A, Tardivel A, Tschopp J. Goutassociated uric acid crystals activate the NALP3 inflammasome. Nature. 2006;440(7081):237-41. https://doi.org/10.1038/ nature 04516.

30. Misawa T, Takahama M, Kozaki T, Lee H, Zou J, Saitoh T, et al. Microtubule-driven spatial arrangement of mitochondria promotes activation of the NLRP3 inflammasome. Nat Immunol. 2013;14(5):454-60. https://doi.org/10.1038/ni.2550.

31. Otani K, Watanabe T, Shimada S, Takeda S, Itani S, Higashimori A, et al. Colchicine prevents NSAID-induced small intestinal injury by inhibiting activation of the NLRP3 inflammasome. Sci Rep. 2016;6:32587. https://doi.org/10.1038/srep32587.
32. Mauro AG, Bonaventura A, Vecchie A, Mezzaroma E, Carbone S, Narayan $\mathrm{P}$, et al. The role of NLRP3 inflammasome in pericarditis: potential for therapeutic approaches. JACC Basic Transl Sci. 2021;6(2):137-50. https://doi.org/10.1016/j.jacbts.2020.11.016. The results of this clinical trial showed that rilonacept led to a rapid resolution of recurrent pericarditis signs and symptoms.

33. https://www.ema.europa.eu/en/documents/product-information/ kineret-epar-product-information_en.pdf. Accessed on April 11 2021.

34. https://www.accessdata.fda.gov/drugsatfda_docs/label/2012/ 103950s5136lbl.pdf. Accessed on April 112021.

35. https://www.accessdata.fda.gov/drugsatfda_docs/label/2008/ 125249lbl.pdf. Accessed on April 112021.

36. Seropian IM, Toldo S, Van Tassell BW, Abbate A. Anti-inflammatory strategies for ventricular remodeling following ST-segment elevation acute myocardial infarction. J Am Coll Cardiol. 2014;63(16):1593603. https://doi.org/10.1016/j.jacc.2014.01.014.

37. Abbate A, Kontos MC, Grizzard JD, Biondi-Zoccai GG, Van Tassell BW, Robati R et al. Interleukin-1 blockade with anakinra to prevent adverse cardiac remodeling after acute myocardial infarction (Virginia Commonwealth University Anakinra Remodeling Trial [VCU-ART] Pilot study). Am J Cardiol. 2010;105(10):1371-7 e1. https://doi.org/10.1016/j.amjcard. 2009.12.059.

38. Abbate A, Van Tassell BW, Biondi-Zoccai G, Kontos MC, Grizzard JD, Spillman DW, et al. Effects of interleukin-1 blockade with anakinra on adverse cardiac remodeling and heart failure after acute myocardial infarction [from the Virginia Commonwealth University-Anakinra Remodeling Trial (2) (VCU-ART2) pilot study]. Am J Cardiol. 2013;111(10):1394400. https://doi.org/10.1016/j.amjcard.2013.01.287.

39. Abbate A, Trankle CR, Buckley LF, Lipinski MJ, Appleton D, Kadariya D, et al. Interleukin-1 blockade inhibits the acute inflammatory response in patients with ST-segment-elevation myocardial infarction. J Am Heart Assoc. 2020;9(5): e014941. https://doi.org/10.1161/JAHA.119.014941.

40. Morton AC, Rothman AM, Greenwood JP, Gunn J, Chase A, Clarke B, et al. The effect of interleukin-1 receptor antagonist therapy on markers of inflammation in non-ST elevation acute coronary syndromes: the MRC-ILA Heart Study. Eur Heart J. 2015;36(6):377-84. https://doi.org/10.1093/eurheartj/ehu272.

41. Toldo S, Mezzaroma E, O'Brien L, Marchetti C, Seropian IM, Voelkel NF, et al. Interleukin-18 mediates interleukin1 -induced cardiac dysfunction. Am J Physiol Heart Circ Physiol. 2014;306(7):H1025-31. https://doi.org/10.1152/ajpheart. 00795.2013 .

42. Van Tassell BW, Arena RA, Toldo S, Mezzaroma E, Azam T, Seropian IM, et al. Enhanced interleukin-1 activity contributes to exercise intolerance in patients with systolic heart failure. PLoS ONE. 2012;7(3): e33438. https://doi.org/10.1371/journal.pone. 0033438.

43. Van Tassell BW, Abouzaki NA, Oddi Erdle C, Carbone S, Trankle $\mathrm{CR}$, Melchior RD, et al. Interleukin-1 blockade in acute decompensated heart failure: a randomized, double-blinded, placebocontrolled pilot study. J Cardiovasc Pharmacol. 2016;67(6):54451. https://doi.org/10.1097/FJC.0000000000000378.

44. Van Tassell BW, Canada J, Carbone S, Trankle C, Buckley L, Oddi Erdle $C$ et al. Interleukin-1 blockade in recently decompensated systolic heart failure: results from REDHART (Recently Decompensated Heart Failure Anakinra Response Trial). Circ Heart Fail. 2017;10(11). https://doi.org/10.1161/ CIRCHEARTFAILURE.117.004373.

45. Imazio M, Andreis A, De Ferrari GM, Cremer PC, Mardigyan $\mathrm{V}$, Maestroni S, et al. Anakinra for corticosteroid-dependent and colchicine-resistant pericarditis: The IRAP (International Registry of Anakinra for Pericarditis) study. Eur J Prev Cardiol. 
2020;27(9):956-64. https://doi.org/10.1177/2047487319 879534. In a 'real world' population of patients with recurrent pericarditis, anakinra was safe and effective in reducing recurrences, emergency department admissions, and hospitalisations.

46. Klein AL, Lin D, Cremer PC, Nasir S, Luis SA, Abbate A, et al. Efficacy and safety of rilonacept for recurrent pericarditis: results from a phase II clinical trial. Heart. 2020. https://doi.org/ 10.1136/heartjnl-2020-317928.

47.• Klein AL, Imazio M, Cremer P, Brucato A, Abbate A, Fang F, et al. Phase 3 trial of interleukin-1 trap rilonacept in recurrent pericarditis. N Engl J Med. 2021;384(1):31-41. https://doi.org/ 10.1056/NEJMoa2027892. The results of this clinical trial showed that rilonacept led to a rapid resolution of recurrent pericarditis signs and symptoms.

48. Alabed S, Cabello JB, Irving GJ, Qintar M, Burls A. Colchicine for pericarditis. Cochrane Database Syst Rev. 2014(8):CD010652. https:// doi.org/10.1002/14651858.CD010652.pub2.

49. Lotrionte M, Biondi-Zoccai G, Imazio M, Castagno D, Moretti $\mathrm{C}$, Abbate $\mathrm{A}$, et al. International collaborative systematic review of controlled clinical trials on pharmacologic treatments for acute pericarditis and its recurrences. Am Heart J. 2010;160(4):662-70. https://doi.org/10.1016/j.ahj.2010.06.015.

50. Imazio M, Brucato A, Cumetti D, Brambilla G, Demichelis B, Ferro $\mathrm{S}$, et al. Corticosteroids for recurrent pericarditis: high versus low doses: a nonrandomized observation. Circulation. 2008;118(6):66771. https://doi.org/10.1161/CIRCULATIONAHA.107.761064.

51. Pereda CA, Nishishinya-Aquino MB, Brito-Garcia N, Del Campo D, Fontecha P, Rua-Figueroa I. Is cotrimoxazole prophylaxis against Pneumocystis jirovecii pneumonia needed in patients with systemic autoimmune rheumatic diseases requiring immunosuppressive therapies? Rheumatol Int. 2021;41(8):141927. https://doi.org/10.1007/s00296-021-04808-4.

52. Dagan A, Langevitz P, Shoenfeld Y, Shovman O. Anakinra in idiopathic recurrent pericarditis refractory to immunosuppressive therapy; a preliminary experience in seven patients. Autoimmun Rev. 2019;18(6):627-31. https://doi.org/10.1016/j.autrev. 2019.01.005.

53. Signa S, D’Alessandro M, Consolini R, Miniaci A, Bustaffa M, Longo C, et al. Failure of anti Interleukin-1 beta monoclonal antibody in the treatment of recurrent pericarditis in two children. Pediatr Rheumatol Online J. 2020;18(1):51. https://doi. org/10.1186/s12969-020-00438-5.

54. Tombetti E, Mule A, Tamanini S, Matteucci L, Negro E, Brucato A, et al. Novel pharmacotherapies for recurrent pericarditis: current options in 2020. Curr Cardiol Rep. 2020;22(8):59. https:// doi.org/10.1007/s11886-020-01308-y.

55. Goletti D, Petrone L, Ippolito G, Niccoli L, Nannini C, Cantini F. Preventive therapy for tuberculosis in rheumatological patients undergoing therapy with biological drugs. Expert Rev Anti Infect Ther. 2018;16(6):501-12. https://doi.org/10.1080/14787210. 2018.1483238 .

56. Kineret (anakinra). https://www.accessdata.fda.gov/drugsatfda_docs/ label/2001/anakamg111401LB.pdf. Last accessed April 8th 2021.

57. Kaiser C, Knight A, Nordstrom D, Pettersson T, Fransson J, Florin-Robertsson E, et al. Injection-site reactions upon Kineret (anakinra) administration: experiences and explanations. Rheumatol Int. 2012;32(2):295-9. https://doi.org/10.1007/ s00296-011-2096-3.
58. Vila AT, Puig L, Fernandez-Figueras MT, Laiz AM, Vidal D, Alomar A. Adverse cutaneous reactions to anakinra in patients with rheumatoid arthritis: clinicopathological study of five patients. Br J Dermatol. 2005;153(2):417-23. https://doi.org/ 10.1111/j.1365-2133.2005.06635.x.

59. Cabral VP, Andrade CA, Passos SR, Martins MF, Hokerberg YH. Severe infection in patients with rheumatoid arthritis taking anakinra, rituximab, or abatacept: a systematic review of observational studies. Rev Bras Reumatol Engl Ed. 2016;56(6):54350. https://doi.org/10.1016/j.rbre.2016.10.001.

60. Salliot C, Dougados M, Gossec L. Risk of serious infections during rituximab, abatacept and anakinra treatments for rheumatoid arthritis: meta-analyses of randomised placebo-controlled trials. Ann Rheum Dis. 2009;68(1):25-32. https://doi.org/10.1136/ard. 2007.083188.

61. Huet T, Beaussier H, Voisin O, Jouveshomme S, Dauriat G, Lazareth I, et al. Anakinra for severe forms of COVID-19: a cohort study. Lancet Rheumatol. 2020;2(7):e393-400. https:// doi.org/10.1016/S2665-9913(20)30164-8.

62. Pontali E, Volpi S, Antonucci G, Castellaneta M, Buzzi D, Tricerri F, et al. Safety and efficacy of early high-dose IV anakinra in severe COVID-19 lung disease. J Allergy Clin Immunol. 2020;146(1):213-5. https://doi.org/10.1016/j.jaci.2020.05.002.

63. Navarro-Millan I, Sattui SE, Lakhanpal A, Zisa D, Siegel CH, Crow MK. Use of anakinra to prevent mechanical ventilation in severe COVID-19: a case series. Arthritis Rheumatol. 2020;72(12):1990-7. https://doi.org/10.1002/art.41422.

64. Cauchois R, Koubi M, Delarbre D, Manet C, Carvelli J, Blasco $\mathrm{VB}$, et al. Early IL-1 receptor blockade in severe inflammatory respiratory failure complicating COVID-19. Proc Natl Acad Sci U S A. 2020;117(32):18951-3. https://doi.org/10.1073/pnas. 2009017117.

65. Cavalli G, De Luca G, Campochiaro C, Della-Torre E, Ripa M, Canetti D, et al. Interleukin-1 blockade with high-dose anakinra in patients with COVID-19, acute respiratory distress syndrome, and hyperinflammation: a retrospective cohort study. Lancet Rheumatol. 2020;2(6):e325-31. https://doi.org/10.1016/S26659913(20)30127-2.

66. Shakoory B, Carcillo JA, Chatham WW, Amdur RL, Zhao H, Dinarello CA, et al. Interleukin-1 receptor blockade is associated with reduced mortality in sepsis patients with features of macrophage activation syndrome: reanalysis of a prior phase III trial. Crit Care Med. 2016;44(2):275-81. https://doi.org/10. 1097/CCM.0000000000001402.

67. Furer V, Rondaan C, Heijstek MW, Agmon-Levin N, van Assen S, Bijl M, et al. 2019 update of EULAR recommendations for vaccination in adult patients with autoimmune inflammatory rheumatic diseases. Ann Rheum Dis. 2020;79(1):39-52. https:// doi.org/10.1136/annrheumdis-2019-215882.

68. Tanriover MD, Akar S, Turkcapar N, Karadag O, Ertenli I, Kiraz S. Vaccination recommendations for adult patients with rheumatic diseases. Eur J Rheumatol. 2016;3(1):29-35. https://doi. org/10.5152/eurjrheum.2016.16100.

Publisher's Note Springer Nature remains neutral with regard to jurisdictional claims in published maps and institutional affiliations. 